\title{
Introduction of Dental Provisional Materials Used in Prosthodontics
}

ISSN: 2637-7764

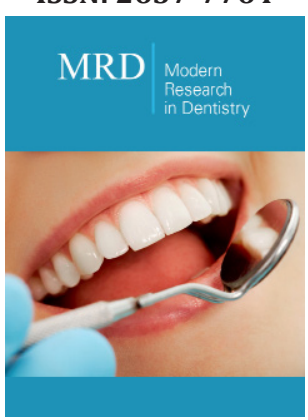

*Corresponding author: Arwa U Alsaggaf, faculty member in prosthodontic department, Maxillofacial Surgery and Diagnostics Department, College of Dentistry, Umm Al Qurra University, Saudi Arabia

Submission: 此 December 05, 2019

Published: 此 December 11, 2019

Volume 4 - Issue 4

How to cite this article: Arwa U Alsaggaf, Introduction of Dental Provisional Materials Used in Prosthodontics. Mod Res Dent. 4(4). MRD.000594.2019.

DOI: 10.31031/MRD.2019.04.000594

Copyright@ Arwa U Alsaggaf, This article is distributed under the terms of the Creative Commons Attribution 4.0 International License, which permits unrestricted use and redistribution provided that the original author and source are credited.

\author{
Arwa Alsaggaf $\mathrm{f}^{1,2 *}$ \\ ${ }^{1}$ College of Dentistry, Umm Al Qurra University, Mecca, Saudi Arabia \\ ${ }^{2}$ Department of Prosthodontics, King's College London, United Kingdom
}

\begin{abstract}
Dental provisional restorations have an important value in prosthodontics field. This review is an
\end{abstract} introduction of that topic.

Keywords: Provisional; Temporary restoration; Prosthodontics; Dental materials

\section{Introduction}

Provisional restorations are employed during the transitional phase between the initial teeth preparation or implant loading and the insertion of the definitive prosthesis [1]. For this reason, provisional restorations were historically referred to as temporary restorations. However, the use of the word "temporary" is controversial [2]. Some critics consider it to be inappropriate because it represents less value than the terms provisional or interim, and it can lead to the misconception that the final prosthesis will represent an immediate and magical remedy for the poorly prepared and fabricated transitional restoration [3-5]. The time that elapses between the placement of a provisional restoration and the definitive prosthesis varies according to the situation. Although long-term use of provisional restorations is not recommended, they are required in some cases. With the implant revolution and increasing demand for periodontal and esthetic surgeries, long-term provisionalization has become mandatory. Having them in use for long time increase the demand for better mechanical properties, wear resistance and esthetics and color stability.

\section{Rational of provisional restorations}

The provisional or interim phase of the treatment is one of the most important aspects of restorative treatment. It is considered a key tool that can be employed to diagnose the success of the definitive treatment. The majority of prosthodontists won't proceed to the definitive prosthesis without transferring the wax-up into a provisional restoration for evaluation and diagnosis purposes [6]. This allows the evaluation of the tooth preparations and its parallelism, proximal contacts, vertical dimension of occlusion, occlusal scheme, interocclusal distance, phonetics, esthetics, and patient satisfaction $[2,6,7]$. Provisional restoration, also, allow the clinician to identify if the preparation offers sufficient retention and resistance forms, if the final prosthesis will have good lip support, and if the anterior guidance is effective.

In the same way, provisional restorations can be employed to evaluate clinicians' and technicians' work, they can also be used to appraise the patient's oral hygiene and oral home care. Proper provisional restoration along with the immediate or early replacement of the missing or extracted teeth will protect the position of the adjacent, opposing, and abutment teeth. Having teeth in stabilized position will protect the occlusion, which has a main effect in mastication. Also, by ensuring that the restorations are of an adequate thickness and good marginal seal, bacterial invasion, thermal insults and salivary penetration to dentinal tubules will be prevented [2,7]. As a result, teeth will be protected from caries and pulp will be sedated and protected while the definitive prosthesis is being fabricated [7].

Regarding tissue and periodontium, provisional restorations assist the clinicians to access and view the proximal area and surgical sites during the surgery. Then, act as a healing matrix 
for the soft tissue that can guide the process by which the tissues are reshaped [8]. It serve as a template that can be controlled and manipulated by the dentist for tissue reshaping. This is mainly needed with implant treatment to give the wanted emergence profile [9-11] and it requires a high-quality provisional restoration [12]. Moreover, it can act as a splint for mobile teeth, by splinting mobile teeth periodontium will be protected and treatment will be facilitated.

\section{Classifications and types of provisional materials}

The materials that are used in provisional restorations in contemporary dental practices can be made of different materials that involve various curing and fabrication techniques. Restorations can be prefabricated or custom made. Prefabricated provisional crowns, such as aluminum shell, nickel chrome, and polycarbonate crowns, are commercially provided in kits that consist of different sizes of anterior, premolar and molar shells [13]. The sizes and shapes of the crowns are determined by the manufacturers. Before choosing the crown for the patient, the measurement of the mesiodistal dimension of the preparation should be taken. The dentist should then adjust the occlusogingival length of the prefabricated crown. Prefabricated provisional crowns are, by definition, poor fitting, especially in terms of marginal adaptation. However, due to the time required to fabricate a bespoke, wellfitting restoration, this method is often preferred by many clinicians who are aware of the fiscal and time constraints that come with running a practice.

These factors combined have led to a prevalence of ill-fitting crowns that fail to achieve ideal contour or occlusal contact $[2,7,14,15]$. To overcome this issue, the clinician should invest time in altering, relining, and polishing the crown before it is cemented. Polymeric resin can be used during the relining process to customize the fit $[2,7,15,16]$. However, prosthodontists and restorative dentists prefer custom-made provisional crowns and prostheses. These crowns can be fabricated using direct (chairside), indirect-direct, or indirect (in laboratory) techniques. The materials that are most commonly used in custom-made restorations are methacrylate resins (polymethyl, polyethyl, vinyl-ethyl \& butyl) and composite materials (bis-acrylic and urethan dimethacrylate), $[2,13,15]$. These materials can be chemically, heat, light or dual cured and will form the focus of this study $[16,17]$.

\section{References}

1. (2005) The glossary of prosthodontic terms. J Prosthet Dent 94: 10-92.

2. Burns DR, Beck DA, Nelson SK (2003) A review of selected dental literature on contemporary provisional fixed prosthodontic treatment: Report of the Committee on Research in Fixed Prosthodontics of the Academy of Fixed Prosthodontics. The Journal of Prosthetic Dentistry 90(5): 474-497.

3. Zinner ID, Trachtenberg DI, Miller RD (1989) Provisional restorations in fixed partial prosthodontics. Dent Clin North Am 33(3): 355-377.

4. Lodding DW (1997) Long-term esthetic provisional restorations in dentistry. Curr Opin Cosmet Dent 4: 16-21.

5. Federick DR (1975) The provisional fixed partial denture. J Prosthet Dent 34(5): 520-526.

6. Gratton DG, Aquilino SA (2004) Interim restorations. Dent Clin North Am 48(2): vii, 487-497.

7. Chalifoux PR (2015) Acrylic and other resins: Provisional restorations. pp. 197-230.

8. Fox CW, Abrams BL, Doukoudakis A (1984) Provisional restorations for altered occlusions. J Prosthet Dent 52(4): 567-572.

9. Parpaiola A, Sbricoli L, Guazzo R, Bressan E, Lops D (2013) Managing the peri-implant mucosa: a clinically reliable method for optimizing soft tissue contours and emergence profile. J Esthet Restor Dent 25(5): 317323.

10. Priest G (2006) Esthetic potential of single-implant provisional restorations: selection criteria of available alternatives. J Esthet Restor Dent 18(6): 326-338; discussion 339.

11. Siadat H, Alikhasi M, Beyabanaki E (2017) Interim prosthesis options for dental implants. J Prosthodont 26(4): 331-338.

12. Santing HJ, Kleverlaan CJ, Werner A, Feilzer AJ, Raghoebar GM et al. (2015) Occlusal wear of provisional implant-supported restorations. Clin Implant Dent Relat Res 17(1): 179-185.

13. Christensen GJ (1996) Provisional restorations for fixed prosthodontics. J Am Dent Assoc 127(2): 249-252.

14. Lui JL, Setcos JC, Phillips RW (1986) Temporary restorations: a review. Oper Dent 11(3): 103-110.

15. Strassler HE (2013) Fixed prosthodontics provisional materials: making the right selection. Compend Contin Educ Dent 34(1): 22-24.

16. Wassell RW, St George G, Ingledew RP, Steele JG (2002) Crowns and other extra-coronal restorations: provisional restorations. Br Dent J 192: 619-622.

17. Comisi JC (2015) Provisional materials: advances lead to extensive options for clinicians. Compend Contin Educ Dent 36(1): 54-59.

For possible submissions Click below: 